Journal of Japanese Language Education and Linguistics

Volume 5 No. 2, 2021, 159-167

e-ISSN: 2615-0840 p-ISSN: 2597-5277

DOI: https://doi.org/10.18196/ijlel.v5i2.12557

https://journal.umy.ac.id/index.php/ijlel/issue/view/797

\title{
Keefektifan Student-Centered Learning (SCL) Metode Cerita dalam Pembelajaran Huruf Kanji Level Menengah
}

\author{
Rosi Rosiah*, Azizia Freda Savana \\ Program Studi Pendidikan Bahasa Jepang, Fakultas Pendidikan Bahasa \\ Jepang, Universitas Muhammadiyah Yogyakarta, Indonesia
}

*Corresponding author email: rosi.rosiah@gmail.com

Direview: 23 Agustus 2021, Direvisi: 28 Agustus 2021, Diterima: 30

Agustus 2021

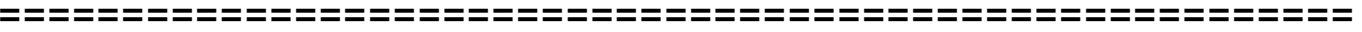

Abstrak

Dalam mempelajari Bahasa Jepang, pembelajaran huruf kanji merupakan salah satu hal yang paling sulit. Oleh karena itu, diperlukan metode dalam mempelajarinya. Telah banyak penelitian mengenai metode pembelajaran huruf kanji. Tapi, isu mengenai huruf kanji masih merupakan isu yang layak untuk diteliti berhubung masih banyak keterbatasan dan hal yang perlu dikembangkan dari metode sebelumnya. Tujuan dari penelitian ini adalah untuk mengetahui keefektifan Student-Centered Learning (SCL) Metode cerita dalam pembelajaran huruf kanji level menengah. Metode yang digunakan kuantitatif eksperimental dengan jumlah partisipan 22 partisipan. Hasil yang setelah dilakukan perlakuan dengan metode cerita selama enam kali. Menunjukan bahwa metode cerita efektif untuk meningkatkan kemampuan terhadap kanji level menengah.
\end{abstract}

Kata kunci: Metode Cerita; Pembelajaran Kanji; Level Menengah 


\begin{abstract}
(Effectiveness of Student-Centered Learning with Story Telling Method for Intermediate Level Kanji Learning) In the mastery ofJapanese language, kanji is one of toughest things to learn. It is the reason why the method in learning Kanji significantly needed. This research reports on experimental study investigating the effect of story of Naritachi on Learning Kanji in the intermediate Japanese Learning Class. The research participants were 22 students of Universitas Muhammadiyah Yogyakarta in second grade. The results of the research are gained after getting the treatment with the method of story conducted in six times. It shows that the method of story telling is effective enough in improving the learning of Kanji in the intermediate level.
\end{abstract}

Keywords: Story telling; Learning of Kanji; Intermediate Level

\title{
PENDAHULUAN
}

Pembelajar bahasa Jepang dari Indonesia yang baru pertama kali mempelajari bahasa tersebut pasti akan langsung menyadari bahwa bahasa Jepang mempunyai karakter huruf yang berbeda dan banyak jenis huruf Jepang yang digunakan dalam kehidupan sehari- hari. Mempelajarinya dimulai dari huruf hiragana, katakana, dan kanji. Pada awal mempelajari bahasa Jepang, huruf hiragana dan katakana akan diajarkan terlebih dahulu. Setelah itu pembelajar baru akan mempelajari huruf kanji. Mempelajari huruf Kanji merupakan hal yang penting dalam dunia pendidikan bahasa Jepang karena merupakan huruf utama yang digunakan dalam kehidupan sehari- hari. Tetapi, dalam mempelajarinya muncul beberapa masalah terutama bagi pembelajar bahasa Jepang yang berasal dari negara yang tidak memiliki budaya kanji seperti pembelajar bahasa Jepang dari Indonesia sehingga sangat penting untuk mengembangkan metode pembelajaran yang efisien dalam pembelajaran kanji (Paxton \& Svetanant, 2013). Beberapa kesulitan yang muncul disebabkan karena, jumlah huruf kanji yang banyak, kanji yang sulit dibaca, cara baca yang banyak, dan kemiripan bentuk (Mori, 2012). Para ahli sudah melakukan beberapa penelitian dan menerapkan beberapa metode Rosiah, R., \& Savana, A. F. (2021). Pembelajaran Kanji 


\section{Journal of Japanese Language Education and Linguistics \\ Volume 5 No. 2, 2021, 159-167}

e-ISSN: 2615-0840 p-ISSN: 2597-5277

DOI: https://doi.org/10.18196/ijlel.v5i2.12557

https://journal.umy.ac.id/index.php/jilel/issue/view/797

dalam mempelajari huruf kanji dari mulai latihan menulis kanji berulangulang (Haththotuwa Gamage, 2003) sampai metode permainan digital menggunakan cerita (Windhaber, 2018). Namun, sampai hari ini metode apa yang paling tepat digunakan dalam pembelajaran kanji masih menjadi topik yang tetap harus didiskusikan. Terdapat beberapa penelitian yang telah meneliti metode pembelajaran kanji dimulai dengan metode menulis di udara. Dalam penelitian ini metode menulis kanji di udara efektif untuk meningkatkan penguasaan kanji pada pembelajar Bahasa Jepang di Jepang (Thomas, 2015). Terdapat juga penelitian yang menyatakan bahwa menulis berulang- ulang merupakan metode yang efektif untuk mempelajari Kanji (Paxton \& Svetanant, 2013), Pembelajaran huruf kanji dengan menggunakan media kartu huruf kanji (Prasetiani \& Diner, 2014). Metode yang cukup terkenal dalam mempelajari kanji yang lainnya adalah metode mnemonic dengan menggunakan metode mnemonic siswa merasa terbantu dalam mempelajari huruf kanji, dan juga dapat meningkatkan pemahaman terhadap huruf kanji secara leksikal dan semantik (Rasiban et al., 2019). Metode mnemonic juga memiliki beberapa kekurangan seperti: banyak penjelasan tentang arti kanji yang hilang dalam strategi mnemonik yang terlalu rumit. Keterbatasan lain dari strategi mnemonic adalah asosiasi yang dibuat dengan arti kanji dan bukan dengan cara membacanya, menyebabkan ketidakmampuan untuk membaca kanji dalam bahasa Jepang.(Rose, 2013). Dalam penelitian lain yang membahas mnemonic dikembangkan pula network mnemonic yang di dalamnya terdapat tahapan elaborasi yang diperlukan untuk memberikan interpretasi imajiner dengan metode cerita. (Esposito, 2017).

Oleh karena itu, dalam penelitian kali ini peneliti mencoba menggunakan metode alternatif yang bisa digunakan dalam mempelajari Bahasa Jepang berupa metode cerita. Metode ini sebelumnya telah diterapkan dalam pembelajaran kanji dasar dengan menggunakan pendekatan teacher centre Learning dan metode ini dinilai efektif dalam pembelajaran kanji dasar 


\section{Journal of Japanese Language Education and Linguistics Volume 5 No. 2, 2021, 159-167 e-ISSN: 2615-0840 p-ISSN: 2597-5277 DOI: https://doi.org/10.18196/ijlel.v5i2.12557 https://iournal.umy.ac.id/index.php/ijlel/issue/view/797}

(Rosiah \& Savana, 2018). Metode cerita yang diterapkan adalah bisa berupa asosiasi dan juga dari asal usul pembentukan Kanji. Dalam penelitian kali ini berbeda dengan penelitian sebelumnya. Metode cerita yang diterapkan dalam pembelajaran kanji level menengah dan pendekatan yang digunakan adalah Student-Centered Learning (SCL), metode ini dipilih karena efektif untuk meningkatkan pemahaman terhadap huruf kanji (Rasiban, 2013). Tujuan dari penelitian ini adalah: untuk mengetahui efektivitas Student Centered Learning (SCL) metode cerita dalam pembelajaran huruf kanji level menengah.

\section{METODOLOGI}

Metode yang digunakan adalah kuantitatif eksperimental dengan post-test dan pre-test design. Tes digunakan untuk memperoleh data. Sampel dalam penelitian ini berjumlah 22 mahasiswa dengan menggunakan random sampling. Data yang diperoleh kemudian diolah dengan menggunakan statistik t table.

\section{HASIL DAN PEMBAHASAN}

Perlakuan kepada kelas eksperimen dilakukan sebanyak enam kali, dengan melalui tahapan sebagai berikut: (1) Membuka perkuliahan, (2) membaca ayat suci Al-Qur'an, (3) memberikan gambaran melalui cerita materi apa yang akan diajarkan pada perkuliahan hari ini mengikuti cerita dari Nihongo sou matome, (5) setelah memberikan overview kanji yang akan dipelajari hari ini. Guru membagi mahasiswa ke dalam kelompok yang terdiri dari empat mahasiswa, (6) setelah membagi ke dalam kelompok masingmasing kelompok dibagikan worksheet tentang kanji dan mereka membuat cerita mengenai kanji yang berasal dari naritachi penyusun kanji hasil lembar 


\section{Journal of Japanese Language Education and Linguistics}

Volume 5 No. 2, 2021, 159-167

e-ISSN: 2615-0840 p-ISSN: 2597-5277

DOI: https://doi.org/10.18196/ijlel.v5i2.12557

https://journal.umy.ac.id/index.php/ijlel/issue/view/797

kerja dari mahasiswa terlampir, (7) setelah masing-masing kelompok mengerjakan worksheet masing-masing kelompok mempresentasikan hasil pekerjaannya dengan membuat cerita, (8) mahasiswa lain yang mendengar memberikan feedback dan masukan kepada kelompok yang presentasi, (9) dosen memberikan feedback, (10) evaluasi berupa tes kecil untuk mengetahui sejauh mana materi yang disampaikan dipahami oleh mahasiwa, dan (11) penutup.

\section{Gambar 1. Worksheet Mahasiswa}

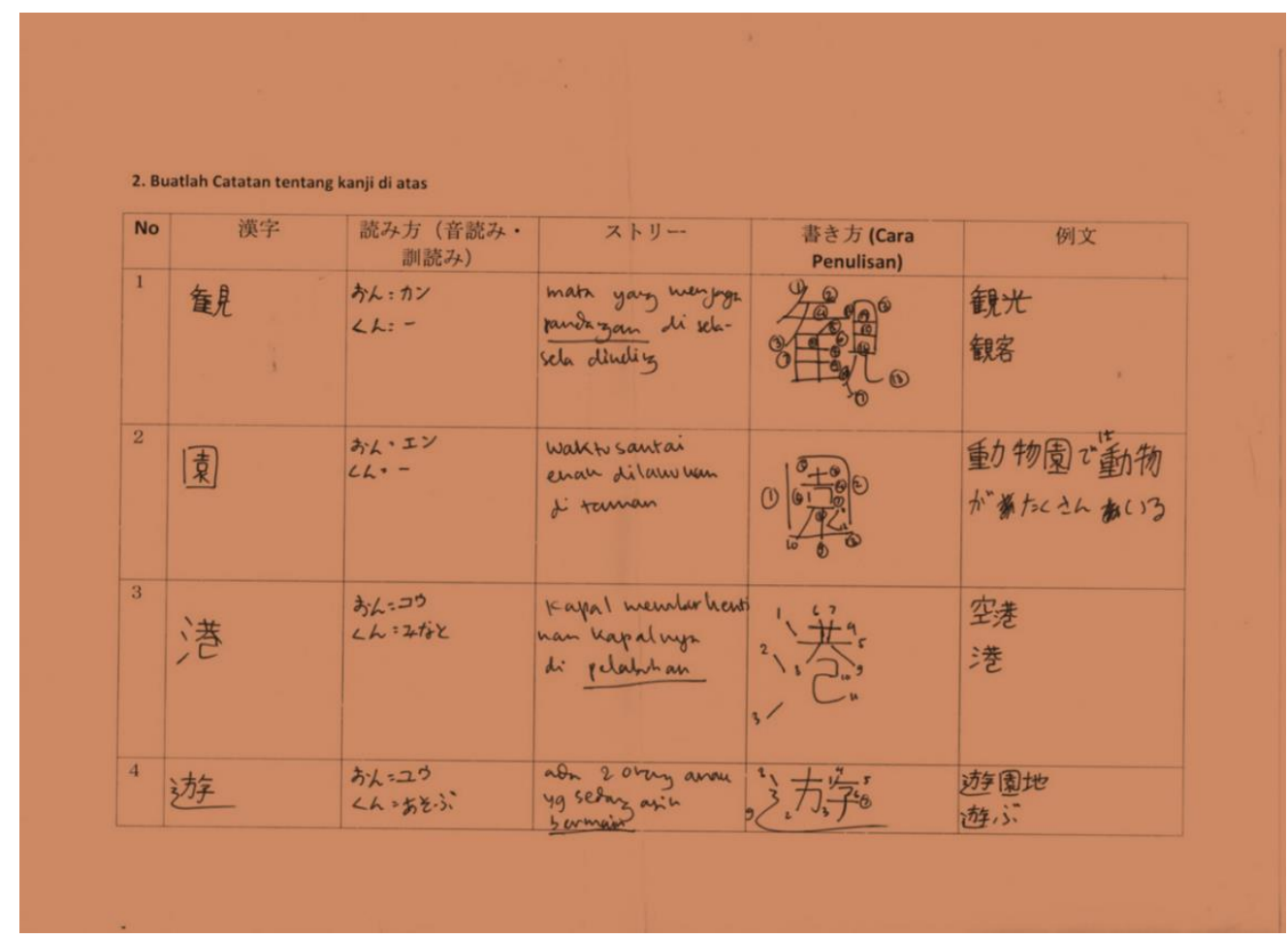

Student-Centered Learning yang diterapkan dalam pembelajaran tersebut diterapkan dalam membuat cerita tentang huruf kanji yang dipelajari secara berkelompok dan siswa diperbolehkan untuk membuat atau mencari cerita melalui internet hal ini sesuai dengan yang dikemukakan dalam sebuah 


\section{Journal of Japanese Language Education and Linguistics Volume 5 No. 2, 2021, 159-167}

e-ISSN: 2615-0840 p-ISSN: 2597-5277

DOI: https://doi.org/10.18196/ijlel.v5i2.12557 https://journal.umy.ac.id/index.php/ijlel/issue/view/797

penelitian bahwa dengan menerapkan SCL dapat meningkatkan capaian yang lebih tinggi dengan melibatkan siswa dengan teknologi dan proyek kelompok yang mendorong mereka untuk melampaui zona nyaman mereka dan menyelesaikan tugas yang telah mereka pilih untuk dikejar. (Overby, 2011). Cerita yang dibuat mahasiswa ada yang berupa ilustrasi dari huruf Kanji tersebut (Mawaddah, 2021).

Berikut hasil dari pre-test dan Post-test setelah mendapatkan perlakuan:

Tabel 1. Hasil Pre-test dan Post-test

\begin{tabular}{lllll}
\hline Group & \multicolumn{2}{c}{ Pre-test } & \multicolumn{3}{c}{ Post-test } \\
& $\mathrm{M}$ & $\mathrm{M}$ & $\mathrm{SD}$ & SEM \\
\hline Experiment (x) & 52,84 & 64,79 & 18,34 & 4 \\
Control (y) & 51,59 & 42,44 & 25,23 & 5,5 \\
\hline
\end{tabular}

Setelah memasukan data ke dalam tabel persiapan, kemudian dihutung Rata- rata kelas eksperimen sebesar 64,79, standar deviasi 18, 34, dan standar eror 4. Kemudian menghitung thitung dan diperoleh thitung sebesar 2.23.

Merumuskan hipotesi Kerja (HK): terdapat perbedaan yang signifikan antara variabel $\mathrm{X}$ dan variabel $\mathrm{Y}$, merumuskan hipotesi nol (Ho): Tidak terdapat perbedaan yang signifikan antara variabel $\mathrm{X}$ dan variabel $\mathrm{Y}$.

Menguji kebenaran kedua hipotesa tersebut dengan membandingkan besarnya $\mathrm{t}_{\text {hitung }}$ dengan $\mathrm{t}_{\text {tabel }}$, dengan terlebih dulu menetapkan derajat kebebasan (degrees of freedom), dengan menggunakan rumus: $\mathrm{df}$ atau $\mathrm{db}=$ $(\mathrm{n}+\mathrm{n})-1,(22+22)-1=43$ dengan menggunakan $\mathrm{df}$ atau db ini maka dapat diperoleh nilai $\mathrm{t}_{\text {tabel }}$ pada taraf signifikansi $5 \%=2$. Ho ditolak Dan Hk diterima. Karena $\mathrm{t}_{\text {tabel }}\left(\mathrm{t}_{\text {hitung }}>\mathrm{t}_{\text {tabel }}\right)$ pada taraf signifikan $5 \%$ maka, $\left(\mathrm{t}_{\text {hitung }}>\mathrm{t}_{\text {tabel }}\right)$ maka 


\section{Journal of Japanese Language Education and Linguistics}

Volume 5 No. 2, 2021, 159-167

e-ISSN: 2615-0840 p-ISSN: 2597-5277

DOI: https://doi.org/10.18196/ijlel.v5i2.12557

https://journal.umy.ac.id/index.php/jilel/issue/view/797

Ho ditolak Dan Hk diterima artinya terdapat perbedaan yang signifikan antara variable X dan Variabel Y. Hal ini berarti bahwa pengajaran Kanji dengan menggunakan metode cerita efektif dalam pelajaran Kanji level menengah.

Temuan dalam penelitian ini melengkapi hasil temuan dari penelitian metode mnemonic untuk pembelajar kanji dasar (Rasiban, 2017). Dalam pembelajaran kanji untuk level menengah dapat menggunakan SCL dengan metode cerita sebagai alternatif metode pembelajaran kanji. Kemudian, hasil penelitian ini pun membuktikan hasil penelitian sebelumnya yang menunjukan bahwa metode pembelajaran kanji dengan cerita mnemonic dengan CALL dapat meningkatkan motivasi pembelajar kanji (Lin, Kajita, \& Mase, 2007).

\section{SIMPULAN}

Student-Centered Learning (SCL) dengan metode cerita merupakan metode yang efektif dalam pembelajaran kanji level menengah dimana hal ini telah terbukti dalam temuan hasil perumusan hipotesa. Penelitian ini belum membahas mengenai respon pembelajar terhadap penerapan metode ini. Sehingga untuk proyeksi penelitian selanjutnya, dapat menelaah mengenai respon pembelajar terhadap metode cerita untuk pembelajaran kanji.

\section{REFERENSI}

Esposito, J. (2017). Mnemonic networks: Multiple paths to learning SinoJapanese characters. The Reading Matrix: An International Online Journal, $17(2)$.

Haththotuwa Gamage, G. (2003). Perceptions of kanji learning strategies. Australian Review of Applied Linguistics, 26(2). https://doi.org/10.1075/aral.26.2.02gam

Lin, N., Kajita, S., \& Mase, K. (2007). Story-based CALL for Japanese kanji characters: A study on student learning motivation. The JALT CALL Journal, 3(2), 25-44. 


\section{Journal of Japanese Language Education and Linguistics Volume 5 No. 2, 2021, 159-167 \\ e-ISSN: 2615-0840 p-ISSN: 2597-5277 \\ DOI: https://doi.org/10.18196/ijlel.v5i2.12557 \\ https://journal.umy.ac.id/index.php/ijlel/issue/view/797}

Mawaddah, A. (2021). Pengenalan huruf kanji dasar dengan media ilustrasi di SMA swasta Dharmawangsa Medan. RESWARA: Jurnal Pengabdian Kepada Masyarakat, 2(2), 255-263. https://doi.org/10.46576/rjpkm.v2i2.1082

Mori, Y. (2012). Five myths about "kanji" and "kanji" learning. Japanese Language and Literature, 46 (1), 143-169. http:jstor.org/stable/41442049

Overby, K. (2011). Student-centered learning. ESSAI, 9. http://dc.cod.edu/essai/vol9/iss1/32

Paxton, S., \& Svetanant, C. (2013). Tackling the kanji hurdle: Investigation of kanji learning in non-kanji background learners. International Journal of Research Studies in Language Learning, 3(3). https://doi.org/10.5861/ijrsll.2013.519

Prasetiani, D., \& Diner, L. (2014). Meningkatkan kemampuan kanji mahasiswa melalui media kartu huruf kanji. IZUMI, 3(2). https://doi.org/10.14710/izumi.3.2.15-21

Rasiban, L. M. (2013). Penerapan student centered learning (SCL) melalui metode mnemonik dengan teknik asosiasi pada mata kuliah kanji dasar. Jurnal Pendidikan Bahasa Dan Sastra, 13(2). https://doi.org/10.17509/bs_jpbsp.v13i2.290

Rasiban, L. M. (2017). Understanding the basic of kanji's meaning through mnemonic method learning. https://doi.org/10.2991/conaplin16.2017.4

Rasiban, L. M., Sudana, D., \& Sutedi, D. (2019). Indonesian students' perceptions of mnemonics strategies to recognize Japanese kanji characters. Indonesian Journal of Applied Linguistics, 8(3). https://doi.org/10.17509/ijal.v8i3.15256

Rose, H. (2013). L2 learners' attitudes toward, and use of, mnemonic strategies when learning Japanese kanji. The Modern Language Journal, 97(4). https://doi.org/10.1111/j.1540-4781.2013.12040.x

Rosiah, R., \& Savana, A. F. (2018). Memorizing kanji through story in shokyu kanji. 2nd International Conference on Japanese Language Education, Literature and Culture, 115-119. 
Journal of Japanese Language Education and Linguistics

Volume 5 No. 2, 2021, 159-167

e-ISSN: 2615-0840 p-ISSN: 2597-5277

DOI: https://doi.org/10.18196/ijlel.v5i2.12557

https://journal.umy.ac.id/index.php/jilel/issue/view/797

Thomas, M. (2015). Air writing as a technique for the acquisition of SinoJapanese characters by second language learners. Language Learning, 65(3). https://doi.org/10.1111/lang.12128

Windhaber, K. (2018). How interactive storytelling in a digital role--playing game can improve the learnability of Japanese Kanji. [Master's Thesis, University of Skovde]. Digitala Vetenskapliga Arkivet. 